\title{
Food consumption patterns of the Vulnerable Socotra cormorant Phalacrocorax nigrogularis indicate minimal overlap with fisheries in the eastern Arabian Gulf
}

\author{
Sabir Bin Muzaffar, Robert Gubiani, Sonya Benjamin, Rashid Alshini \\ Ahmad Al-Romithi and Faisal Humaid Al KaAbi
}

\begin{abstract}
Historically cormorants have come into direct conflict with fisheries because of their feeding habits. The Socotra cormorant Phalacrocorax nigrogularis is a regionally endemic seabird restricted to the Arabian Gulf and coastal Oman, and is categorized as Vulnerable on the IUCN Red List. The species is perceived as being detrimental to local fisheries and is therefore persecuted. We studied the diet and estimated the number of Socotra cormorants breeding on Siniya Island, Umm Al Quwain, United Arab Emirates, to determine their impact on local fisheries. Regurgitated fish loads were collected during the breeding seasons of 2011-2012 and 2012-2013, and the biomass of fish consumed by the Socotra cormorant population was estimated. The diet comprised seven species of fish, with sailfin flying fish Parexocoetus mento and blue-stripe sardine Herklotsichthys quadrimaculatus dominating in 2011-2012 and anchovies (Encrasicholina spp.) dominating in 2012-2013. Biomass of fish loads was higher in 2011-2012 compared to 2012-2013, although mean biomass of fish loads did not differ. Dominant fish species in the cormorant's diet were either used as baitfish or were non-target species in the fisheries. The low overlap between the diet of the Socotra cormorant and the fish landed by the fisheries suggests that the cormorant's impact on fisheries is minimal. Conservation strategies to protect the birds and their feeding areas could safeguard populations of this species from further declines.
\end{abstract}

Keywords Arabian Gulf, diet, fish biomass, fish landings, fishery interactions, impact, Phalacrocorax nigrogularis, Socotra cormorant

\section{Introduction}

Cormorants (Phalacrocoracidae) are piscivorous birds found in coastal areas or inland waters (Cramp, 1977;

\footnotetext{
Sabir Bin Muzaffar (Corresponding author), Robert Gubiani, Sonya Benjamin, Ahmad AL-Romithi and FaIsal Humaid Al KaAbi Department of Biology, College of Science, United Arab Emirates University, Al Ain, United Arab Emirates E-mail s_muzaffar@uaeu.ac.ae

Rashid ALShiHi Marine Environment Research Department, Ministry of Environment and Water, Umm Al Quwain, United Arab Emirates

Received 26 February 2015. Revision requested 31 March 2015

Accepted 1 May 2015. First published online 8 October 2015
}

Johnsgard, 1993; Nelson, 2005). They have frequently come into conflict with fishing communities because of apparent competition for fish (Nettleship \& Duffy, 1995; Liordos et al., 2005; Östman et al., 2013). Commercial fisheries can experience declines in fish stocks as a result of such competition (Barrett et al., 1990; Suter, 1994; Glahn \& Brugger, 1995; Glahn \& Stickley, 1995; Price \& Nickum, 1995; Weseloh et al., 1995; Östman et al., 2013). Cormorants may limit recruitment of declining fish stocks (Barrett et al., 1990); prey on baits used in lobster traps or on fishing hooks, thus reducing capture rates (Price \& Nickum, 1995); feed from aquaculture ponds housing a variety of farmed fish (Price \& Nickum, 1995); feed on the prey species of commercial fish (Östman et al., 2013); and cause significant damage to fishers' nets while diving in pursuit of fish (Nettleship \& Duffy, 1995).

Other studies, however, have demonstrated that cormorants have a positive effect on fisheries and ecosystem dynamics (Suter, 1994, 1995a,b; Liordos \& Goutner, 2008). They prey on fish species that are not targeted by humans (e.g. Liordos \& Goutner, 2008), feed on fish of smaller size classes (Liordos \& Goutner, 2008; Troynikov et al., 2013), selectively feed on and remove sick fish from farms (Nettleship \& Duffy, 1995), and cause density-dependent regulation of fish, thereby enhancing fish diversity and ecosystem functioning (Suter, 1994, 1995a,b). Fishers generally perceive cormorants to be a threat to fisheries (Stickley \& Andrews, 1989; Liordos et al., 2005; Nelson, 2005); for example, Mississippi catfish farmers believed that doublecrested cormorants Phalacrocorax auritus were the greatest threat to farmed fish in ponds (Glahn \& Brugger, 1995), and fishers of the Amvrakikos Gulf, Greece, believed that cormorants were the primary cause of decline in commercial fish stocks (Liordos et al., 2005). Although some of their perceptions are well founded (Leopold et al., 1998), others are baseless (Dalton et al., 2009).

The Socotra cormorant Phalacrocorax nigrogularis is a regionally endemic species found in the Arabian Gulf, the Gulf of Oman and adjoining regions (Javed \& Khan, 2003; BirdLife International, 2012). It is categorized as Vulnerable on the IUCN Red List, based on significant population declines since the 1980s (BirdLife International, 2012). The cormorants are surface-diving piscivores (Cramp, 1977), 
and anecdotal information suggests that their diet probably includes sardines Sardinella spp., bigeye Selar crumenophthalmus and yellowtail scads Atule mate, silversides Atherinomorus lacunosus, spotted halfbeaks Hemiramphus far and streaked rabbitfishes Siganus javus (Jennings, 2010). Disturbance at the breeding colonies is regarded as a major threat to the species, and many colonies have gone extinct as a result of oil exploitation and construction (Jennings, 2010). Collection of eggs and chicks occurs in many of the western colonies, including Abu Dhabi (Jennings, 2010; Wilson, 2012), and recreational shooting of adults seems to be a common practice (Jennings, 2010) although this has not been quantified. Egg collection, hunting of chicks or adults, and disturbance to the breeding habitat are all prohibited under United Arab Emirates Federal Law \#24 (1999).

The diet of seabirds varies between adults and chicks, and chick-provisioning offers insight into fish availability, distribution patterns and long-term changes in the oceanic environment (Barrett et al., 1990; Montevecchi, 1993). The diet of chicks has therefore been used in many seabird studies to examine feeding and foraging ecology (Schreiber \& Burger, 2002). Cormorants regurgitate food loads (consisting of intact or partly digested food) and pellets (containing feathers, otoliths or bones) at their nesting sites. Both have been used to determine diet, although pellets provide a higher degree of accuracy (Zijlstra \& Van Eerden, 1995) provided libraries of fish otoliths are available. Regurgitated food can also be valuable in identifying dietary components, and is considered to be a suitable index of available diet (Barati, 2009; Emmrich \& Düttmann, 2011).

The Arabian Gulf is a shallow, highly saline and relatively warm marine system with rapid turnover; it supports fish communities that are species depauperate compared to other shallow waters at similar latitudes (Sheppard, 1993; Grandcourt, 2012). Artisanal, recreational and commercial fishing are carried out there, targeting mostly reef fish, including groupers (Serranidae), seabreams (Sparidae), emperors (Lethrinidae), snappers (Lutjanidae), sweetlips and grunts (Haemulidae), jacks (Carangidae) and parrotfishes (Scaridae; Carpenter et al., 1997; Grandcourt, 2012). Species such as Sardinella longiceps are also exploited as baitfish, although the extent of this exploitation is not reported (MOEW, 2014). In recent years sharks and other elasmobranchs have also been targeted as part of an unregulated market in the United Arab Emirates (Jabado et al., 2015). Fisheries statistics are reported at the family level, precluding the estimation of species-specific catch data (MOEW, 2014). The lack of species-specific catch and trade data is regarded as an impediment to adequate fishery management (Jabado et al., 2015).

Many fish species are exploited at unsustainable rates in the Arabian Gulf (Grandcourt, 2012; EAD, 2013a; Jabado et al., 2015). Populations of the Socotra cormorant could influence fish stocks by targeting bait or commercial fish species. However, a clear understanding of ecological and sociological factors could help to facilitate sustainable coexistence of cormorants (or other seabirds) and humans (Van Eerden et al., 1995) in the Arabian Gulf. We studied the diet of Socotra cormorant chicks to better understand the species' role in the Arabian Gulf and its impact on the commercial fishery of the United Arab Emirates.

\section{Study area}

Within the Arabian Gulf the largest breeding concentrations of Socotra cormorants occur within the Gulf of Salwa. Bahrain's Hawar Islands complex hosted a population of c. 27,000 pairs during 2005-2006 (Jennings, 2010; Fig. 1), and several Saudi Arabian coastal islands hosted 30,00040,000 pairs (Jennings, 2010). Colonies in the western United Arab Emirates collectively host c. 12,000 pairs on 3-6 islands in Abu Dhabi (EAD, 2012, 2013a,b), and a single colony on Siniya Island in Umm Al Quwain (Fig. 1) is estimated to host 28,000-35,00o pairs (Muzaffar, 2014). Although current trends suggest that Siniya Island may have a larger breeding population, we still consider the Hawar Islands to be the largest breeding colony, given the variability in the size of the breeding population between years (Pilcher et al., 2003; Jennings, 2010; Muzaffar, 2014).

This study was part of a greater effort to understand breeding, foraging ecology and conservation of the species on Siniya Island (Fig. 1; see Muzaffar et al., 2012, 2013, 2015 for details of the site). The colony of Socotra cormorants is restricted to the north-central part of the island. The habitat consists of mixed desert scrub (Haloxylon-Arthrocnemum macrostachyum complex), loose sandy gravel and plantations of Acacia tortilis, Prosopis juliflora and Prosopis cineraria. The island is under the jurisdiction of the Umm $\mathrm{Al}$ Quwain Municipality and the Ministry of Environment and Water. The nearest islands with breeding Socotra cormorants are $329 \mathrm{~km}$ west, in Abu Dhabi (Jennings, 2010; Fig. 1).

\section{Methods}

Fish loads were collected during the 2011-2012 and 20122013 breeding seasons. We approached nesting cormorants during 14.00-16.00, which elicited regurgitation (normally they would attempt to feed the chicks directly). In the 2011-2012 breeding season sampling was carried out early (17 October 2011), when most chicks $(>75 \%)$ had hatched but were still small and associated with nests, and late (19 November 2011), when chicks were $>_{2}$ weeks old and many were still associated with nest sites but most were forming creches (Gubiani et al., 2012). Thus, there was a better representation of the diet of chicks of various sizes during 2011-2012. In 2012-2013 fish loads were collected only on 


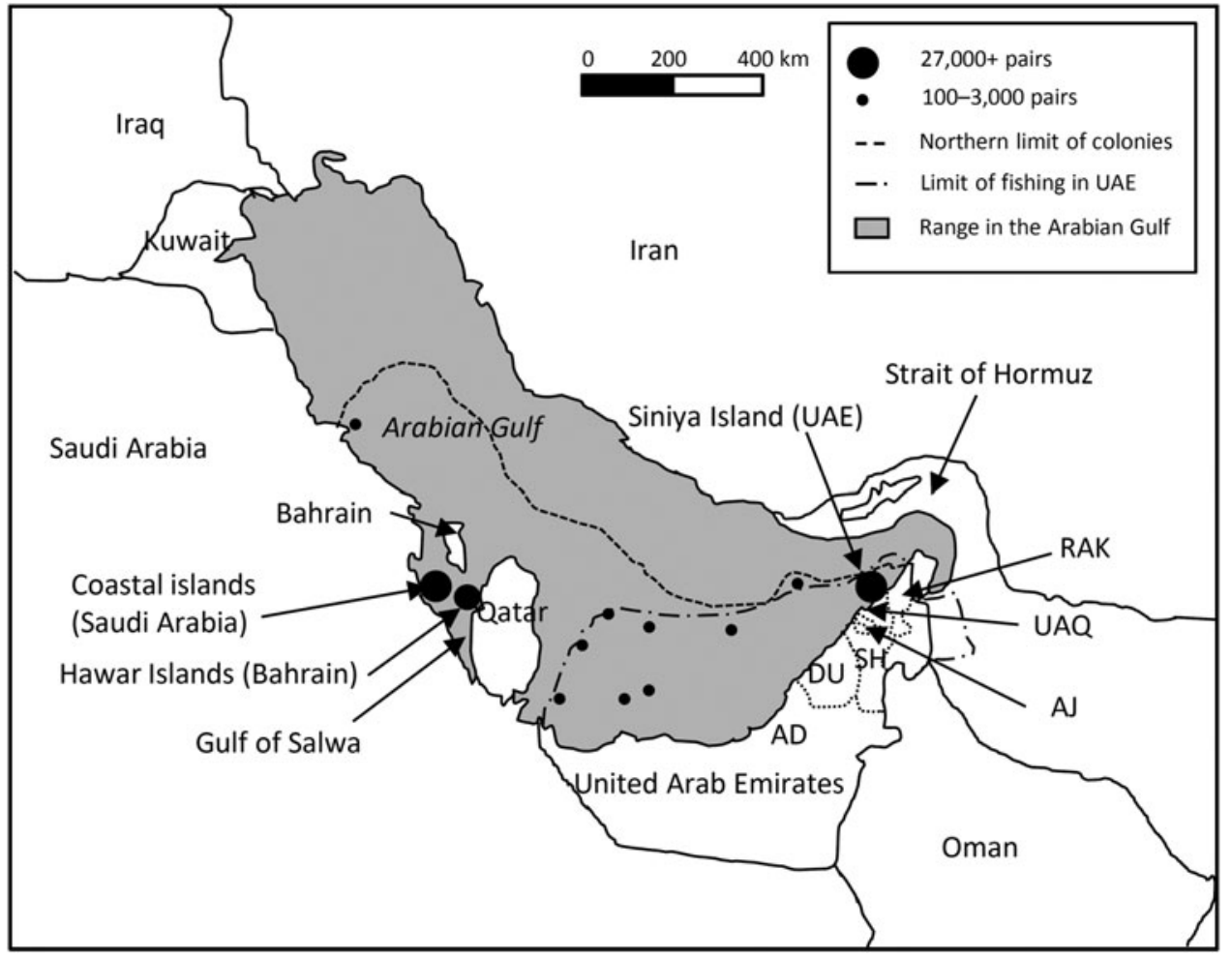

FIG. 1 Distribution of the Socotra cormorant Phalacrocorax nigrogularis in the Arabian Gulf (BirdLife International, 2012). $\mathrm{AD}, \mathrm{Abu}$ Dhabi; DU, Dubai; SH, Sharjah; AJ, Ajman; UAQ, Umm Al Quwain; RAK, Ras Al Khaimah two dates during the breeding season (11 November 2012 and 21 February 2013), arbitrarily defined as early and late. Our observations suggested that one species dominated fish loads throughout the season, and therefore the small sample size could still be representative. Each fish load was placed in a labelled ziplock bag and either analysed on site, away from the colony (2011-2012), or frozen within 2-3 hours and processed later in the laboratory (2012-2013). Each species was photographed, and representative specimens were retained to confirm their identification later.

Loads that contained partly digested fish were not used in the analyses. We analysed a total of 27 fish loads containing 330 individual fish in 2011-2012 and 12 fish loads containing 239 individual fish in 2012-2013. Although we recognize that these sample sizes are small and there is potential for bias, we believe that the collection method made sampling representative although it had the potential to miss rare species in the diet.

Each individual fish was identified to the lowest possible taxonomic level using FAO (1974), Carpenter et al. (1997) and FishBase (Froese \& Pauly, 2014), and their standard lengths were measured. The biomass of each species was estimated using the equation

$$
\text { Biomass }=a S L^{b}
$$

where $\mathrm{SL}=$ standard length. Values of fitting parameters a and $\mathrm{b}$ were obtained from published references for the species or genus in FishBase (Froese \& Pauly, 2014). The total number of fish per load, mean biomass of individual fish from all fish loads, and mean biomass of fish loads were pooled for a given season and compared between years using one-way ANOVA to examine inter-year differences in diet. Relative abundance and fish biomass were also compared between years. Biomass of early and late fish loads was compared using one-way ANOVA.

Breeding population data for the Socotra cormorant were obtained from our ongoing monitoring activity (Muzaffar et al., 2012, 2013). The total breeding populations during the 2011-2012 and 2012-2013 seasons were estimated based on the density and area of occupancy of breeding pairs. Area of occupancy was mapped in Google Earth (Google Inc., Mountain View, USA) and calculated in $\mathrm{m}^{2}$. The density of nesting birds was taken from Muzaffar et al. (2012). Variance was estimated following Anderson et al. (2013). Hatching success was estimated to be $58.7 \%$ for $2011-2012$ (Muzaffar et al., 2012) and $81.2 \%$ for 2012-2013 (S.B. Muzaffar, unpubl. data). Fledging success (the proportion of hatchlings that survived to fledging) was estimated to be 65.6 (Muzaffar et al., 2012) and 82.1\% (S.B. Muzaffar, unpubl. data) for 2011-2012 and 2012-2013, respectively. Fourteen study plots, each containing $10-30$ nests, were monitored once every 2 weeks to determine the hatching success and fledging success in 2011-2012 (Muzaffar et al., 2012). Chicks were considered fledged if they were no longer observed in the nest after 35 days (see details in Muzaffar et al., 2012). Juveniles and non-breeding adults were estimated to comprise 23 and $12 \%$, respectively, of the breeding population each year, based on the age structure of other species of cormorants (Nelson, 2005). Variance in the estimates of the total numbers of chicks and fledglings was based on variation in the hatching and fledging success in 
14 plots containing 141 nests in 2011-2012 (Muzaffar et al., 2012) and four plots containing 53 nests in 2012-2013 (S.B. Muzaffar, unpubl. data). Variance in the juvenile, nonbreeding adult and breeding adult populations was estimated by resampling the product of the density of nests in the 14 plots (Muzaffar et al., 2012) and the area 1,000 times with replacement (Manly, 1991).

The number of meals per chick was estimated to be three per day, based on our observations, and it was assumed that one meal represented one fish load. The biomass consumed by the total population of chicks was estimated based on the mean biomass of fish in fish loads consumed during each breeding season (120 days). The biomass consumed by fledged chicks was calculated over the entire year $(245$ days), assuming none of the fledged chicks died before the following year.

Consumption of fish by juveniles and non-breeding and breeding adults was estimated based on allometric calculations in Nagy (1987) and then extrapolated to the total population of those age classes in 2011-2012 and 2012-2013. Field metabolic rate (FMR) was calculated using the following equation:

$$
\text { FMR }=3.201 \times \text { mass }^{0.719}(\text { Nagy, 1987) }
$$

The mass of a Socotra cormorant was set at 1,500 g, based on our measurements of adult individuals (S.B. Muzaffar, unpubl. data). Energy density of prey was set at $5.7 \mathrm{~kJ} \mathrm{~g}^{-1}$, following Danckwerts et al. (2014). All quantities of fish consumed were converted to tonnes and extrapolated to the entire population in each year.

Fishing occurs extensively within the waters of the United Arab Emirates (Fig. 1) and some areas are fished by more than one emirate. Fisheries statistics for 2011 were obtained from the Ministry of Environment and Water (MOEW, 2014). Fisheries statistics for 2012 were not available and were estimated based on the mean incremental increase in fish landings during 2008-2011 available from the MOEW. These data provide total fish catches in all seven emirates (Abu Dhabi, Dubai, Sharjah, Ajman, Umm Al Quwain, Ras Al Khaimah and Fujairah), including total catch, total catch of demersal fish and total catch of pelagic fish. Based on foraging data for Socotra cormorants (Muzaffar, 2014) we determined that individuals breeding on Siniya Island were fishing in the waters of Dubai, Sharjah, Ajman, Umm Al Quwain and Ras Al Khaimah. We therefore pooled the landing data for these five emirates to compare total biomass consumption by Socotra cormorants in relation to fish landings. The accuracy of the data for fish catches is not indicated on the MOEW website, and thus we have presented them as raw total catch, without any standard error. All statistical analyses were conducted in Minitab 14.1 (Informer Technologies Inc., Shingle Springs, USA).

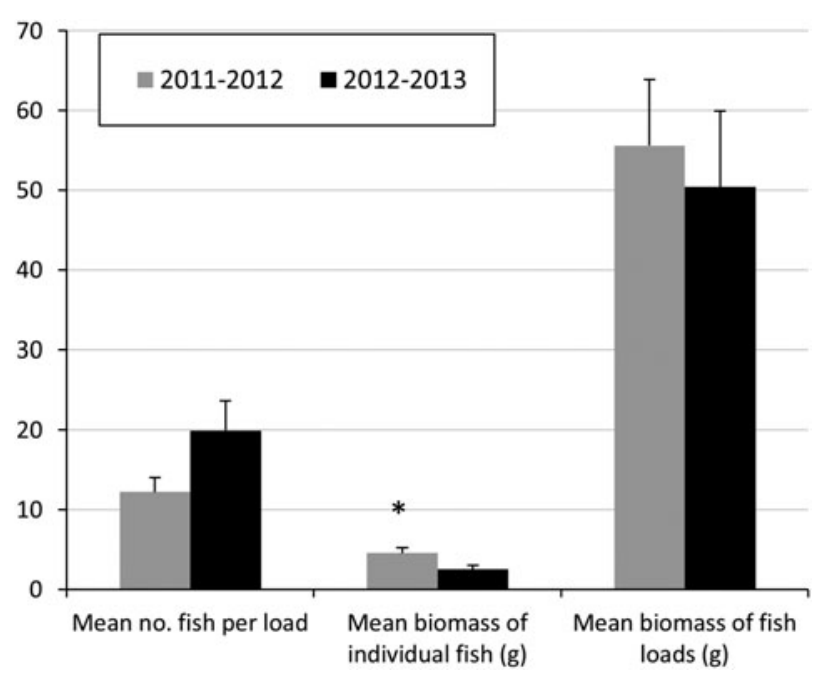

FIG. 2 Comparison of fish consumption by Socotra cormorants on Siniya Island (Fig. 1) during the 2011-2012 and 2012-2013 breeding seasons. The asterisk indicates significant difference at $\alpha=0.05$.

\section{Results}

Fish loads contained 1-66 fish, with a mean of 12.2 in 20112012 and 19.2 in 2012-2013; the difference was not significant (Fig. 2). Mean biomass of individual fish was significantly higher in 2011-2012 (4.58 g) compared to 2012-2013 (2.53 g; one-way ANOVA, $\mathrm{n}=569, \mathrm{~F}=14.97, \mathrm{P}<0.001$ ). Total biomass per fish load, however, was not significantly different between years.

Seven species of fish were recorded in the fish loads: sailfin flying fish Parexocoetus mento, blue-stripe sardine Herklotsichthys quadrimaculatus, anchovies Encrasicholina spp., pink ear emperor Lethrinus lentjan, pickhandle barracuda Sphyraena jello, congaturi halfbeak Hyporhamphus limbatus, and bigeye scad Selar crumenophthalmus (Fig. 3). There was little overlap in the composition of the diet between the 2 years. Sailfin flying fish were the most numerically dominant species in 2011-2012 (70\%), whereas anchovies dominated in 2012-2013 (98.32\%). Estimates of fish biomass revealed that the blue-stripe sardine was more prevalent as prey in $2011-2012(41.47 \%)$, followed by the sailfin flying fish $(27.96 \%)$. In 2011-2012 the mean biomass of fish loads increased from 2.00 to $11.13 \mathrm{~g}$ during the chick-rearing period (one-way ANOVA, $\mathrm{F}=117.45, \mathrm{P}<0.001$ ). The diet was composed primarily of sailfin flying fish $(99.01 \%)$ in the early part of the season, followed by a switch to blue-stripe sardine $(60.75 \%)$ and pink ear emperor $(39.25 \%)$. No such change was evident in the 2012-2013 season, and anchovies remained the most consumed species throughout the season (100\% early in the season and $94.1 \%$ later). Biomass of fish per load decreased between early $(3.53 \mathrm{~g})$ and later $(1.55 \mathrm{~g})$ in the season (one-way ANOVA, F = 374.89, $\mathrm{P}<0.001$ ).

Total consumption of fish was estimated to be $11,626 \pm$ $\mathrm{SE} 72 \mathrm{t}$ in 2011-2012 and 18,764 $\pm \mathrm{SE} 126 \mathrm{t}$ in 2012-2013. 

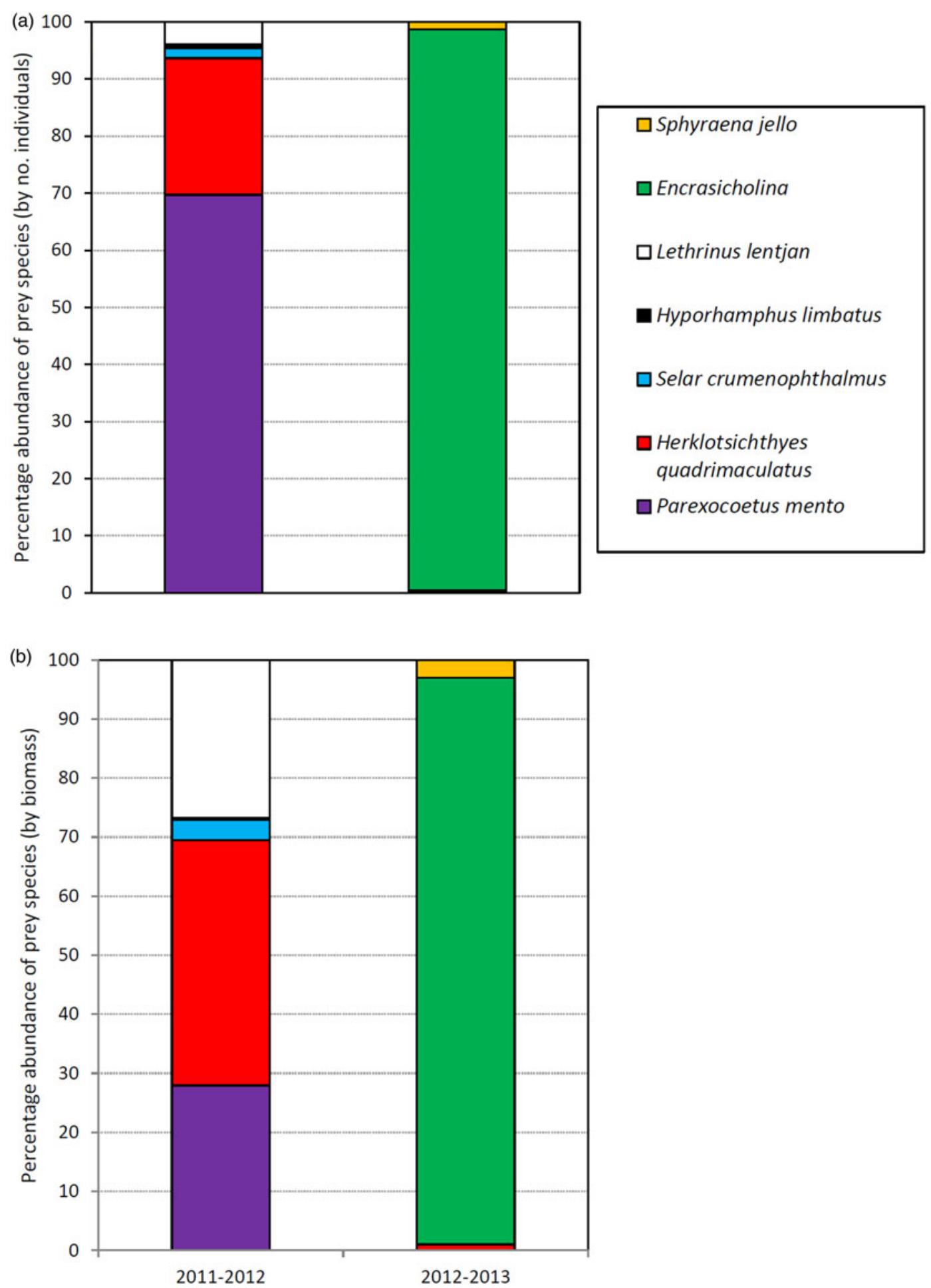

FIG. 3 Comparison of the diet of Socotra cormorants on Siniya Island (Fig. 1) during the 2011-2012 and 2012-2013 breeding seasons in terms of (a) number of individuals and (b) biomass of prey species.

Chicks consumed c. $808 \pm \mathrm{SE}_{32}$ and $1,491 \pm \mathrm{SE}_{51} \mathrm{t}$ during the chick-rearing period in 2011-2012 and 2012-2013, respectively (Table 1). Fledglings consumed 2,344 \pm SE 93 and 5,960 \pm SE $206 \mathrm{t}$ in 2011-2012 and 2012-2013, respectively. Total fish biomass consumed by the Socotra cormorant population of Siniya Island was $11,626 \pm S E 72$ and $18,764 \pm$ SE $126 \mathrm{t}$ in 2011-2012 and 2012-2013, respectively.
The total tonnage of fish landed by the commercial fisheries from the foraging areas of Socotra cormorants was $56,557 \mathrm{t}$ in 2012 and 62,972 $\mathrm{t}$ in 2013. Most of the catch was composed of demersal fishes $(32,781 \mathrm{t}$ in 2012, $36,500 t$ in 2013) and none of the commercial catches included any of the species that were dominant in the diet of Socotra cormorants (MOEW, 2014; Table 2). 
TABle 1 Population size of Socotra cormorants Phalacrocorax nigrogularis on Siniya Island, Umm Al Quwain, United Arab Emirates (Fig. 1), and the estimated biomass consumed by the population during the 2011-2012 and 2012-2013 breeding seasons.

\begin{tabular}{|c|c|c|c|c|c|c|}
\hline Breeding season & Chicks & Fledged chicks & Juveniles & $\begin{array}{l}\text { Non-breeding } \\
\text { adults }\end{array}$ & $\begin{array}{l}\text { Breeding } \\
\text { adults }\end{array}$ & Total \\
\hline \multicolumn{7}{|c|}{$\begin{array}{l}\text { Population size (no. of } \\
\text { individuals } \pm \text { SE) }\end{array}$} \\
\hline 2011-2012 & $40,157 \pm 1,606$ & $26,343 \pm 1,053$ & $12,950 \pm 730$ & $6,981 \pm 411$ & $56,644 \pm 364^{1}$ & $102,919 \pm 665$ \\
\hline $2012-2013$ & $82,210 \pm 2,844$ & $67,412 \pm 2,332$ & $17,388 \pm 980$ & $9,374 \pm 553$ & $75,602 \pm 760^{2}$ & $169,776 \pm 1,401$ \\
\hline \multicolumn{7}{|c|}{$\begin{array}{l}\text { Tonnes of fish biomass } \\
\text { consumed } \pm \text { SE }\end{array}$} \\
\hline $2011-2012$ & $808 \pm 32$ & $2,343 \pm 93$ & $1,439 \pm 101$ & $776 \pm 57$ & $6,260 \pm 50$ & $11,626 \pm 72$ \\
\hline $2012-2013$ & $1,491 \pm 51$ & $5,960 \pm 206$ & $1,921 \pm 135$ & $1,036 \pm 76$ & $8,356 \pm 105$ & $18,764 \pm 126$ \\
\hline
\end{tabular}

${ }^{1} 28,322$ breeding pairs

${ }^{2} 37,801$ breeding pairs

\section{Discussion}

Cormorant-fisheries interactions remain a contentious issue in wildlife management. Increases in populations of great cormorants Phalacrocorax carbo are usually met with aggressive management intervention, primarily to protect fisheries (Vetemaa et al., 2010; Emmrich \& Düttman, 2011). Fine-scale studies have helped to refute or confirm the suspected negative impact of cormorants on fisheries (Van Eerden et al., 1995; Vetemaa et al., 2010; Emmrich \& Düttman, 2011). The Arabian Gulf has a relatively small volume and is semiisolated, with a species-poor fish fauna derived from the adjacent Arabian Sea (Sheppard, 1993; Grandcourt, 2012). Commercial fishing in the Arabian Gulf has increased in recent years as a result of development in the Middle East (Grandcourt, 2012; Jabado, 2014), and is dominated by medium-large reef fish species belonging to the Serranidae, Sparidae, Lethrinidae, Lutjanidae and Carangidae (Carpenter et al., 1997; EAD, 2012; Grandcourt, 2012).

The breeding population of Socotra cormorants of Siniya Island may have a significant impact on its food webs, utilizing a variety of small fish of length $45-180 \mathrm{~mm}$. The diet of chicks varied significantly between years, suggesting that the species is a generalist, feeding opportunistically on abundant fish species. The local fisheries primarily land large demersal or reef fishes, whereas the diet of cormorant chicks consists of small, pelagic fishes, mostly of low commercial value, and therefore the impact of the cormorants on fisheries is minimal.

\section{Chick diet}

Socotra cormorants appear to be a generalist species, with significant variation in the diet of chicks. The diet consisted mostly of sailfin flying fish and blue-stripe sardines in 20112012 and anchovies in 2012-2013. The fishes consumed were small (biomass 2-6 g), with significantly lower individual biomass recorded in 2012-2013, when anchovies comprised $98 \%$ of the diet. The mean biomass of fish loads was not significantly different between years, however, indicating that parents provided approximately the same amount of food to their growing chicks, compensating for differences in the biomass of individual fish species. As partly digested fish were not included in the analyses, rare species were probably not adequately sampled and only dominant species were quantified, and therefore further studies are needed to characterize the breadth of the diet of cormorants.

Many cormorant species exhibit opportunistic dietary patterns over the course of a year (Nelson, 2005; Liordos \& Goutner, 2008), suggesting adaptability to changing fish stocks. Jennings (2010) reported that sardines, halfbeaks, scads and rabbitfish formed part of the diet of Socotra cormorants in the Hawar Islands in Bahrain. Although these species were not recorded in our study, some are from the same families (pelagic species of Hemiramphidae, Clupeidae and Carangidae). This indicates that cormorants from different colonies may have dissimilar diets, depending on the available local fish resources, seasonality and year, although the major fish groups targeted may be similar. Intercolony variation in diet has been widely reported in other cormorant (Liordos \& Goutner, 2008) and seabird species (Schreiber \& Burger, 2002) and requires further investigation in Socotra cormorants.

Mean biomass of fish load increased significantly during the latter part of the 2011-2012 season. This was probably a reflection of the breeding phase, with larger chicks compelling parents to provide larger fish loads. The change in fish biomass also reflected a switch from mainly flying fish to sardines, as parents provided more nutritious food to their growing chicks (Barati, 2009; Emmrich \& Düttmann, 2011). The diets of great cormorants are also known to change in response to the nutritional requirements of growing chicks during the course of a season (Liordos \& Goutner, 2008; Barati, 2009; Emmrich \& Düttmann, 2011).

In contrast, in 2012-2013 the biomass of fish loads declined as the season progressed. A larger sample size could have provided a better understanding of how fish loads change in relation to fish availability; however, we speculate that difference in the timing of breeding between 2011-2012 and 2012-2013 could explain our observations. In 2012-2013 breeding started c. 2 
TABLE 2 Overlap between major fish species targeted commercially or as baitfish and the diet of Socotra cormorants on Siniya Island, United Arab Emirates (Fig. 1).

\begin{tabular}{|c|c|c|}
\hline Species & Fishery & $\begin{array}{c}\text { Cormorant } \\
\text { diet }\end{array}$ \\
\hline \multicolumn{3}{|l|}{ Carnagidae } \\
\hline Carangoides bajad & Commercial & \\
\hline Selar crumenophthalmus & & $\begin{array}{l}\text { Minor } \\
\text { component }\end{array}$ \\
\hline \multicolumn{3}{|l|}{ Haemulidae } \\
\hline Scomberoides commersonnianus & Commercial & \\
\hline Diagramma pictum & Commercial & \\
\hline \multicolumn{3}{|l|}{ Lethrinidae } \\
\hline Lethrinus lentjan & Commercial & $\begin{array}{l}\text { Minor } \\
\text { component }\end{array}$ \\
\hline Lethrinus nebulosus & Commercial & \\
\hline \multicolumn{3}{|l|}{ Portunidae } \\
\hline Portunus pelagicus & Commercial & \\
\hline \multicolumn{3}{|l|}{ Scombridae } \\
\hline Scomberomorus commerson & Commercial & \\
\hline \multicolumn{3}{|l|}{ Serranidae } \\
\hline Epinephelus coidoides & Commercial & \\
\hline \multicolumn{3}{|l|}{ Sphyraenidae } \\
\hline Sphyraena jello & Commercial & $\begin{array}{l}\text { Minor } \\
\text { component }\end{array}$ \\
\hline \multicolumn{3}{|l|}{ Engraulidae } \\
\hline Encrasicholina spp. & Baitfish & $\begin{array}{l}\text { Major } \\
\text { component }\end{array}$ \\
\hline \multicolumn{3}{|l|}{ Clupeidae } \\
\hline Sardinella longiceps & Baitfish & \\
\hline Herklotsichthys quadrimaculatus & & $\begin{array}{l}\text { Major } \\
\text { component }\end{array}$ \\
\hline \multicolumn{3}{|l|}{ Exocetidae } \\
\hline Parexocoetus mento & & $\begin{array}{l}\text { Major } \\
\text { component }\end{array}$ \\
\hline \multicolumn{3}{|l|}{ Hemiramphidae } \\
\hline Hyporhamphus limbatus & & $\begin{array}{l}\text { Minor } \\
\text { component }\end{array}$ \\
\hline
\end{tabular}

weeks later and peak breeding was observed in December, compared to November in 2011-2012. Anchovies in the Arabian Gulf migrate westwards from the northern emirates (including Umm Al Quwain) in December and become less abundant after January (MOEW, pers. comm.). Thus, a more prolonged breeding season in 2012-2013 could have caused a decline in the local stocks of anchovies, which was reflected in the lower biomass of fish loads observed late in the season. A more detailed investigation of seasonal changes in diet is necessary to better understand dietary shifts in breeding colonies of Socotra cormorants.

\section{Impact on fisheries}

Great cormorants have contrasting impacts on local fish resources. Increasing populations caused a decline in fish stocks in an estuary in Estonia over a 10-year period (Vetemaa et al., 2010). However, Engström (2001) showed that although great cormorant populations were linked with fish densities, predation pressure from cormorants did not cause a decline in fish densities in Lake Ymsen, Sweden. Thus, the perceived impact of cormorants on fisheries is often incorrect. Troynikov et al. (2013) showed that great cormorants selected fish of size classes that did not overlap with the fish targeted by the European perch Perca fluviatilis fishery in Lithuania. Furthermore, great cormorants may select different species from those targeted by fisheries in Greece (e.g. Liordos \& Goutner, 2008). The fish landings of the United Arab Emirates have been increasing steadily since the 1970s (Beech et al., 2005; Grandcourt, 2012). The fisheries statistics reports for the emirate of Abu Dhabi suggests that the bulk of the fish catch comprises orange-spotted trevally Carangoides bajad, Talang queenfish Scomberoides commersonnianus, painted sweetlips Diagramma pictum, pink ear emperor, spangled emperor Lethrinus nebulosus, blue crab Portunus pelagicus, narrowbarred Spanish mackerel Scomberomorus commerson, orange-spotted grouper Epinephelus coioides and pickhandle barracuda (collectively $>3,960$ t per year, $83 \%$ of total catch in Abu Dhabi in 2012; EAD, 2013b). Similar data for other emirates are not available but it may be assumed that they exploit similar species, given the widespread popularity of these species (Beech et al., 2005; Grandcourt, 2012). The sailfin flying fish, which comprised $27.9 \%$ of the diet of Socotra cormorants in 2011-2012, is not exploited by the fishery, and the blue-stripe sardine, which dominated the diet (41.5\%), is exploited for consumption, baitfish or animal feed but is not reported in the fisheries statistics (Grandcourt, 2012; EAD, 2013a; MOEW, 2014). Similarly, anchovies, which dominated the Socotra cormorant's diet in 2012-2013 (95.9\%), are used as baitfish or animal feed but their exploitation is not of commercial importance. It is possible that Socotra cormorants may influence commercial fish species indirectly by eating younger individuals or the prey of the larger fish. Our study does not provide evidence of significant consumption of any larval stages of commercially important fish. The two commercially exploited species found in the diet, S. jello and L. lenjtans, constituted minor components of the diet. Selar crumenophthalmus is not reported in the fisheries statistics, although other species of scads (e.g. Atule bajad) are targeted at low levels ( $<60 \mathrm{t}$ annually; EAD, 2012) by the commercial fishery. Anchovies were the most important component of the diet in the 2012-2013 breeding season, suggesting that there could be conflict between cormorants and fishers. However, species that are considered baitfish (e.g. Sardinella longiceps, Encrasicholina spp.) seem to be captured opportunistically and at sufficiently low levels that they are not reported in the fishery statistics (EAD, 2013a; MOEW, 2014). Reports of fishers' attitudes towards Socotra cormorants are anecdotal, and formal surveys are needed to determine perceptions and attitudes of fishers. 
The total quantity of fish consumed by the Socotra cormorant population breeding on Siniya Island is small compared to the total tonnage of exploited species (MOEW, 2014; Table 1). Juveniles and breeding and non-breeding adults leave the colony to disperse as far as Abu Dhabi in the west and across the Strait of Hormutz into the Gulf of Oman in the east (Muzaffar, 2014), thus they forage away from the breeding colony during April-September, exploiting other regions of the Gulf. Based on the little overlap between the diet of cormorant chicks and commercially exploited species, and the relatively small biomass consumed by cormorants, we suggest that the species has a low impact on the commercial fisheries of the United Arab Emirates. The negative perception among fishers of the effects of cormorants on fish stocks in the United Arab Emirates or the greater Arabian Gulf is misplaced.

Measures must be taken to ensure sustainability of fisheries and to protect the Socotra cormorant, especially on Siniya Island. As the United Arab Emirates hosts $41 \%$ of the global population of the species, protection and better understanding of Siniya Island and other colonies in Abu Dhabi are essential. Siniya Island hosts the largest population of breeding Socotra cormorants in the United Arab Emirates (Jennings, 2010). Long-term studies examining diet of this and other seabird species will help to understand the role of Socotra cormorants and other seabirds in shaping the food webs of the Arabian Gulf.

\section{Acknowledgements}

We thank the Ministry of Environment and Water for providing funding to SBM and logistical support for this work. Additional support for the project was received through the Mohammad Bin Zayed Species Conservation Fund and the United Arab Emirates University/National Research Foundation grant to SBM. We thank the Umm Al Quwain Municipality for issuing permits to work on the island. All field procedures adhere to international standards that were approved by the Animal Research Ethics Committee (Protocol No. A18-12) of UAE University, the Ministry of Environment and Water, and the Umm Al Quwain Municipality.

\section{References}

Anderson, D.W., Henny, C.J., Godinez-Reyes, C., Gress, F., Palacios, E.L., Santos Del Prado, K. et al. (2013) Size and distribution of the California brown pelican metapopulation in a non-ENSO year. Marine Ornithology, 41, 95-106.

BARATI, A. (2009) Diet and growth of chicks of the great cormorant, Phalacrocorax carbo, at Ramsar, northern Iran (Aves: Phalacrocoracidae). Zoology in the Middle East, 46, 29-36.

Barrett, R.T., Røv, N., Loen, J. \& Montevecchi, W.A. (1990) Diets of shags Phalacrocorax aristotelis and cormorants P. carbo in
Norway and possible implications for gadoid stock recruitment. Marine Ecology Progress Series, 66, 205-218.

Beech, M., Al Abdussalam, T. \& Hoolihan, J.P. (2005) Marine fish. In Emirates: A Natural History (eds P. Hellyer \& S. Aspinall), pp. 261-281. Trident Press, Abu Dhabi, United Arab Emirates.

Birdife International (2012) Phalacrocorax nigrogularis. In The IUCN Red List of Threatened Species v. 2012.2. Http://www. iucnredlist.org [accessed 4 September 2014].

Carpenter, K.E., Krupp, F., Jones, D.A. \& Zajonz, U. (1997) FAO Species Identification Guide for Fishery Purposes. The Living Marine Resources of Kuwait, Eastern Saudi Arabia, Bahrain, Qatar, and the United Arab Emirates. Food and Agriculture Organization of the United Nations, Rome, Italy.

Cramp, S. (1977) Handbook of the Birds of Europe, the Middle East, and North Africa: The Birds of the Western Palearctic. Oxford University Press, Oxford, UK.

Dalton, C.M., Ellis, D. \& Post, D.M. (2009) The impact of double-crested cormorant (Phalacrocorax auritus) predation on anadromous alewife (Alosa pseudoharengus) in south-central Connecticut, USA. Canadian Journal of Fisheries and Aquatic Sciences, 66, 177-186.

Danckwerts, D.K., McQuaid, C.D., Jaeger, A., McGregor, G.K., Dwight, R., Le Corre, M. \& Jaquemet, S. (2014) Biomass consumption by breeding seabirds in the western Indian Ocean: indirect interactions with fisheries and implications for management. ICES Journal of Marine Science. Http://dx.doi.org/10. 1093/icesjms/fsuo93.

Emmrich, M. \& Düttmann, H. (2011) Seasonal shifts in diet composition of great cormorants Phalacrocorax carbo sinensis foraging at a shallow eutrophic inland lake. Ardea, 99, 207-216.

ENGSTRÖM, H. (2001) Long term effects of cormorant predation on fish communities and fishery in a freshwater lake. Ecography, 24, 127-138.

EAD (2012) Annual Report. Environment Agency-Abu Dhabi, United Arab Emirates.

EAD (2013a) Annual Fisheries Statistics Report for Abu Dhabi Emirate 2012. Terrestrial and Marine Biodiversity Sector, Environment Agency-Abu Dhabi, United Arab Emirates.

EAD (2013b) Annual Report. Environment Agency-Abu Dhabi, United Arab Emirates.

FAO (1974) FAO Species Identification Sheets for Fishery Purposes. Eastern Indian Ocean Fishing Area 57 and Western Central Pacific Fishing Area 71. Food and Agriculture Organization of the United Nations, Rome, Italy.

Froese, R. \& Pauly, D. (eds) (2014) FishBase. Http://www.fishbase. org [version (04/2014)].

Glahn, J.F. \& BRUGGER, K.E. (1995) The impact of double-crested cormorants on the Mississippi Delta catfish industry: a bioenergetics model. Colonial Waterbirds, 18, 168-175.

Glahn, J.F. \& Stickley, JR, A.R. (1995) Wintering double-crested cormorants in the Delta region of the Mississippi: population levels and their impact on the catfish industry. Colonial Waterbirds, 18 , 137-142.

Grandcourt, E. (2012) Reef fish and fisheries in the Gulf. In Coral Reefs of the Gulf: Adaptation to Climatic Extremes (eds B.M. Riegl \& S.J. Purkis), pp. 127-162. Springer, London, UK.

Gubiani, R., Benjamin, S. \& Muzaffar, S.B. (2012) First record of cannibalism in Socotra cormorants (Phalacrocorax nigrogularis): large, immature birds opportunistically feed on younger conspecifics. Waterbirds, 35, 338-341.

JABADO, R. (2014) Assessing the fishery and ecology of sharks in the United Arab Emirates. PhD thesis. United Arab Emirates University, Al Ain, United Arab Emirates.

Jabado, R., Al Ghais, S.M., Hamza, W., Henderson, A.C., Spaet, J.L.Y., SHIVjI, M.S. \& HANNER, R.H. (2015) The trade in sharks and 
their products in the United Arab Emirates. Biological Conservation, 181, 190-198.

JAVED, S. \& KHAN, S.B. (2003) Important Islands for Bird Conservation in the Abu Dhabi Emirate. Unpublished report. Environmental Research and Wildlife Development Agency, Abu Dhabi, United Arab Emirates.

Jennings, M.C. (2010) Atlas of the breeding birds of Arabia. Fauna of Arabia, 25, 216-221.

Johnsgard, P.A. (1993) Cormorants, Darters and Pelicans of the World. Smithsonian Institution Scholarly Press, Washington, DC, USA.

Leopold, M.F., van Damme, C.J.G. \& van der Veer, H.W. (1998) Diet of cormorants and the impact of cormorant predation on juvenile flatfish in the Dutch Wadden Sea. Journal of Sea Research, 40, 93-107.

Liordos, V. \& Goutner, V. (2008) Habitat and temporal variation in diet of great cormorant nestlings in Greek colonies. Waterbirds, 31, 424-437.

Liordos, V., Zogaris, S. \& Papandopoulos, D. (2005) Great cormorant Phalacrocorax carbo food and human perceptions at the Amvrakikos Gulf, western Greece. In Proceedings of the 7 th International Conference on Cormorants, 23-26 November 2005, Villeneuve, Switzerland (eds M.R. Van Eerden, S. van Rijn \& V. Keller). Wetlands International-IUCN Cormorant Research Group, Lelystad, The Netherlands.

Manly, B.F.J. (1991) Randomization and Monte Carlo Methods in Biology. Chapman \& Hall, London, UK.

MOEW (Ministry of Environment and Water) (2014) Statistics. Http://www.moew.gov.ae/en/knowledge-and-statistics. aspx\#page $=1$ [accessed 19 August 2015].

Montevecchi, W.A. (1993) Birds as indicators of change in marine prey stocks. In Birds as Monitors of Environmental Change (eds R. W. Furness \& J.D. Greenwood), pp. 217-266. Chapman \& Hall, London, UK.

Muzaffar, S.B. (2014) Ecology and conservation of the Socotra cormorant (Phalacrocorax nigrogularis) in the eastern Arabian Gulf. In Seabirds and Songbirds: Ecology, Conservation and Migratory Behavior (ed. G. Mahala), pp. 135-146. Nova Science Publishers, Inc., New York, USA.

Muzaffar, S.B., Gubiani, R. \& Benjamin, S. (2012) Reproductive performance of the Socotra cormorant (Phalacrocorax nigrogularis) on Siniya Island, United Arab Emirates: planted trees increase hatching success. Waterbirds, 35, 626-630.

Muzaffar, S.B., Benjamin, S. \& Gubiani, R. (2013) The impact of fox and feral cat predation on the population viability of the threatened, endemic Socotra cormorant on Siniya Island, United Arab Emirates. Marine Ornithology, 41, 171-177.

Muzaffar, S.B., Gubiani, R. \& Benjamin, S. (2015) Nest location influences hatching success in the Socotra cormorant (Phalacrocorax nigrogularis) on Siniya Island, United Arab Emirates. Wildlife Research, 42, 13-18.

NAGY, K.A. (1987) Field metabolic rate and food requirement scaling in mammals and birds. Ecological Monographs, 57, 111-128.

Nelson, J.B. (2005) Pelicans, Cormorants and their Relatives: The Pelecaniforms. Oxford University Press, Oxford, UK.

Nettleship, D.N. \& Duffy, D.C. (1995) Cormorants and human interactions: an introduction. Colonial Waterbirds, 18, 3-6.

Östman, Ö., Boström, M.K., Bergström, U., Andersson, J. \& Lunneryd, S.-G. (2013) Estimating competition between wildlife and humans-a case of cormorants and coastal fisheries in the Baltic Sea. PLoS ONE, 8(12), e83763.
Pilcher, N.J., Phillips, R.C., Aspinall, S., Al-Madany, I., King, H., Hellyer, P. et al. (2003). Hawar Islands Protected AreaManagement Plan. Manama, Kingdom of Bahrain.

Price, I.M. \& Nickum, J.G. (1995) Aquaculture and birds: the context for controversy. Colonial Waterbirds, 18, 33-45.

Schreiber, E.A. \& Burger, J. (eds) (2002) Biology of Marine Birds. CRC Press, Boca Raton, USA.

Shep pard, C.R.C. (1993) Physical environment of the Gulf relevant to marine pollution: an overview. Marine Pollution Bulletin, 27, 3-8.

Stickley, A.R. \& Andrews, K.J. (1989) Survery of Mississippi catfish farmers on means, effort and costs to repel fish-eating birds from ponds. Eastern Wildlife Damage Control Conference, 4, 105-108.

SutER, W. (1994) Overwintering waterfowl on Swiss lakes: how are abundance and species richness influenced by trophic status and lake morphology? Hydrobiologia, 279/28o, 1-14.

Suter, W. (1995a) The effect of predation by wintering cormorants Phalacrocorax carbo on grayling Thymallus thymallus and trout (Salmonidae) populations: two case studies from Swiss rivers. Journal of Applied Ecology, 32, 29-46.

Suter, W. (1995b) Are cormorants Phalocrocorax carbo wintering in Switzerland approaching carrying capacity? An analysis of increase patterns and habitat choice. Ardea, 83, 255-266.

Troynikov, V., Whitten, A., Gorfine, H., Pütys, Ž., JAKUBAVIČIÚTÉ, E., LOŽYs, L. \& DAINYS, J. (2013) Cormorant catch concerns for fishers: estimating the size-selectivity of a piscivorous bird. PLoS ONE, 8(11), e77518.

UAE Federal Law \# 24 (1999) Protection and Development of the Environment. United Arab Emirates.

Van Eerden, M.R., Koffijberg, K. \& Platteeuw, M. (1995) Riding on the crest of the wave: possibilities and limitations for a thriving population of migratory cormorants Phalacrocorax carbo in man-dominated wetlands. Ardea, 83, 1-9.

Vetemaa, M., Eschbaum, R., Albert, A., Saks, L., Verlin, A., JÜRENS, K. et al. (2010) Changes in fish stocks in an Estonian estuary: overfishing by cormorants? ICES Journal of Marine Science, 67, 1972-1979.

Weseloh, D.V., Ewins, P.J., Struger, J., Mineau, P., Bishop, C.A., Postupalsky, S. \& Ludwig, J.P. (1995) Double-crested cormorants of the Great Lakes: changes in population size, breeding distribution and reproductive output between 1913 and 1991. Colonial Waterbirds, 18, 48-59.

Wilson, K.D.P. (2012) Breeding of Socotra cormorant at Umm Qasr Island. The Phoenix, 28, 26-28.

Zijlstra, M. \& Van Eerden, M.R. (1995) Pellet production and the use of otoliths in determining the diet of cormorants Phalacrocorax carbo sinensis: trials with captive birds. Ardea, 83, 123-131.

\section{Biographical sketches}

Sabir Bin Muzaffar's research focuses on the movement ecology, breeding biology and conservation of birds. RoBert GUBiani works on a variety of environmental projects relating to biodiversity and conservation. SONYA BENJAMIN's research interests focus on determining the effectiveness of common ecological mitigation measures often proposed as a means of alleviating adverse impacts from developmental pressures in the Middle East. Rashid ALSHini's research interests focus on marine organisms, including sea birds, and marine ecosystems and conservation. Ahmed Al-Romithi has worked on the diet and foraging of cormorants. FAISAL AL KAABI is interested in the feeding ecology of cormorants. 